\title{
The threshold current in the intrathecal space to elicit motor response is lower and does not over- lap that in the epidural space: a porcine model
}

\author{
[Le courant seuil qui produit une réponse motrice est plus faible dans l'espace intrathécal
}

que dans l'espace péridural et ne le chevauche pas : un modèle porcin]

Ban C.H. Tsui MD MSc FRCPC, Alese Wagner BSc, Brendan Finucane MB CHB FRCPC

Purpose: Using electrical epidural stimulation, a current of I to 10 $\mathrm{mA}$ is required to confirm the presence of the tip of an epidural catheter in the epidural space. The purpose of this study was to examine the hypothesis that the threshold current required to elicit a motor response in the intrathecal space is significantly lower than that in the epidural space in a porcine model.

Methods: Four 20-kg pigs were used in this experiment. Eighteen gauge, insulated, Tuohy needles were advanced into the epidural space using the loss of resistance technique at five different spinal levels in each pig. When the epidural space was entered, an electrical current was applied to the needle and increased progressively until a motor response was elicited. The needle was then further advanced until cerebrospinal fluid (CSF) was observed or until the needle had been advanced a maximum of $\mathrm{I} \mathrm{cm}$. At this point, the current was reapplied and increased until motor activity was evident.

Results: A total of 20 needles were inserted in four pigs. The current required to produce a motor response in the epidural space was $3.45 \pm 0.73 \mathrm{~mA}$ (mean $\pm \mathrm{SD}$ ). The current required to produce a motor response in the intrathecal space (entry confirmed by the presence of CSF) was $0.38 \pm 0.19 \mathrm{~mA}$ (mean $\pm \mathrm{SD}$ ). Two needles were advanced $\mathrm{I} \mathrm{cm}$ without obtaining CSF but the current thresholds were similar to those obtained when CSF was evident (0.4 mA and $0.3 \mathrm{~mA}$, respectively).

Conclusion: The threshold current of an insulated needle required to elicit a motor response in the intrathecal space, was significantly $(P<0.01)$ lower than that in the epidural space in a porcine model.
Objectif : En utilisant une stimulation péridurale électrique, un courant de I à 10 mA est nécessaire pour confirmer la présence de la pointe d'un cathéter dans l'espace péridural. Notre objectif était de vérifier l'hypothèse voulant que le courant seuil nécessaire pour obtenir une réponse motrice dans l'espace intrathécal soit significativement plus faible que dans l'espace péridural chez un modèle porcin.

Méthode : Quatre porcs de 20 kg ont été utilisés. Des aiguilles Tuohy isolées, de calibre 18, ont été poussées dans l'espace péridural selon la technique de perte de résistance à cinq niveaux différents chez chaque animal. Une fois l'aiguille introduite, un courant électrique était appliqué et augmenté progressivement jusqu'à l'obtention d'une réaction motrice. L'aiguille était ensuite avancée plus loin jusqu'à ce qu'on observe du liquide céphalo-rachidien (LCR) ou de $1 \mathrm{~cm}$ tout au plus. À ce point, le courant était réappliqué et augmenté jusqu'à ce que l'activité motrice soit évidente.

Résultats : Un total de 20 aiguilles ont été insérées chez quatre porcs. Le courant requis pour produire une réponse motrice dans l'espace péridural a été de 3,45 $\pm 0,73 \mathrm{~mA}$ (moyenne \pm écart type). Le courant requis dans l'espace intrathécal (entrée confirmée par la présence de $L C R$ ) a été de 0,38 $\pm 0,19 \mathrm{~mA}$ (moyenne \pm écart type). Deux aiguilles ont été poussées de $1 \mathrm{~cm}$ sans qu'on observe de $L C R$, mais les courants minimaux ont été similaires à ceux qu'on a obtenus en présence de $L C R(0,4 \mathrm{~mA}$ et $0,3 \mathrm{~mA}$, respectivement).

Conclusion : Le courant seuil, transmis par une aiguille isolée, nécessaire pour produire une réponse motrice dans l'espace intrathécal a été significativement $(P<0,0$ I) plus faible que dans l'espace péridural chez un modèle porcin.

From the Department of Anesthesiology and Pain Medicine, University of Alberta, Edmonton, Alberta, Canada.

Address correspondence to: Dr. Ban C.H. Tsui, Department of Anesthesiology and Pain Medicine, University of Alberta Hospitals, 3B2.32 Walter Mackenzie Health Science Centre, 8440-112 Street, Edmonton, Alberta T6G 2B7, Canada. E-mail: btsui@ualberta.ca Supported in part by the Education and Research Fund, Department of Anesthesiology and Pain Medicine, University of Alberta Hospitals, Edmonton, Canada, and Clinical Investigatorship Award, Alberta Heritage Foundation for Medical Research, Alberta, Canada. Accepted for publication November 21, 2003.

Revision accepted April 12, 2004. 


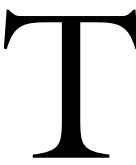

HORACIC epidural needle and catheter placement is performed routinely in awake adults. ${ }^{1}$ In contrast, epidural anesthesia is commonly performed under sedation or general anesthesia in pediatric patients for a number of practical reasons. ${ }^{2,3}$ Paresthesia and pain on injection are early warning signs of the presence of a needle in the vicinity of a nerve root or the spinal cord in awake patients, but we cannot use these valuable signs in anesthetized patients. ${ }^{l}$ As a result, there is considerable apprehension about performing central neuraxial blockade in anesthetized or heavily sedated patients because of the potential for neurological complications. Kasai et al. recently reported a case of spinal cord damage following a single-shot thoracic epidural in an anesthetized child. ${ }^{4}$ Although the child regained normal function with time, this alerts us to the risk of performing thoracic epidurals in anesthetized children and reinforces the need for an alternate warning sign when placing epidurals in anesthetized patients. ${ }^{5}$

The use of electrical stimulation (ES) for peripheral nerve blocks theoretically reduces the risk of nerve damage because the needle does not have to make physical contact with the nerve in order to produce a motor response. However, there are no studies demonstrating a reduction of nerve damage when using a nerve stimulator. When performing peripheral nerve blocks, a motor response following stimulation with a current less than $0.5 \mathrm{~mA}$ is generally accepted as indicative of a catheter/needle being positioned close enough to the nerve to produce an effective block. ${ }^{6}$ In contrast, previous studies have confirmed epidural catheter placement using much higher currents $(1-10 \mathrm{~mA})$ during electrical epidural stimulation (Tsui test). ${ }^{7-12}$ These studies also hypothesized that when using ES, a motor response evoked by a low current $(<\mathrm{lmA})$ could serve as a warning sign of a needle or catheter approaching a nerve root or entering the subarachnoid space. ${ }^{7-12}$ Passannante et al. reported a case of total spinal block and permanent neurological damage resulting from an accidental subarachnoid and intraneural local anesthetic injection at a low current $(0.2 \mathrm{~mA})$ when a nerve stimulatorguided interscalene brachial plexus block was performed during general anesthesia. ${ }^{13}$ In previous case reports, using ES, we demonstrated that a motor response occurs with: a) subarachnoid catheter placement at $0.4 \mathrm{~mA} ;{ }^{8}$ b) subdural catheter placement at $0.3 \mathrm{~mA} ;{ }^{9}$ and c) catheter tip placement in close proximity to nerve roots at $0.5 \mathrm{~mA} .{ }^{10}$ However, this has never been demonstrated in a formal study. In this pilot study, a porcine model was used to test the hypothesis that the threshold current required to elic- it a motor response in the intrathecal space is lower than that in the epidural space.

\section{Materials and methods}

Following Ethics approval from the Animal Care Committee in our institution, five separate needles were inserted at five different spinal levels in four farm-bred pigs, weighing approximately $20 \mathrm{~kg}$, from the low-lumbar to high-thoracic region in each pig (high-thoracic, mid-thoracic, low-thoracic, high-lumbar and low-lumbar levels). The total number of needle insertions was 20. After each pig was sedated with ketamine (10 $\mathrm{mg} \cdot \mathrm{kg}^{-1}$ given intramuscularly) and anesthetized with isoflurane (1.5 to 3\%) in oxygen and air, each anesthetized pig was then placed in the lateral position (Figure 1) and an 18-gauge insulated Tuohy needle (Pajunk, Dyna Medical Corp, ON, Canada) was inserted into the epidural space, using the loss of resistance technique (LOR) with air (limited to less than $1 \mathrm{~mL}$ ). When the epidural space was identified, the needle lumen was checked to ensure the absence of cerebrospinal fluid (CSF). Entry into the epidural space was also confirmed by the ease of threading a 20 -gauge epidural catheter through the needle into the epidural space ( $5 \mathrm{~cm}$ beyond the needle). Upon removal of the catheter, an electrical current $(1 \mathrm{~Hz}$, pulse width 0.2 msec) via a constant current nerve stimulator (Maxistim, Life-tech Inc., Stafford, TX, USA) was applied to the needle and progressively increased from zero until motor activity (lower limb movement for lumbar insertions, abdominal muscle movement for mid- and low-thoracic insertions and intercostal muscle movement for high-thoracic insertions) was evident. Subsequently, the nerve stimulator was turned off and the needle was advanced until CSF was obtained or until the needle was advanced a maximum of $1 \mathrm{~cm}$. When CSF was obtained the needle lumen was capped to prevent excessive loss of CSF. Current was then reapplied to the insulated needle and progressively increased until motor activity was evident. Upon achieving the threshold current, all needles devoid of CSF were advanced approximately $1 \mathrm{~mm}$ at a time whilst continuing to apply ES, until contact was made with the bone.

\section{Statistical analysis}

Data are presented as mean $\pm \mathrm{SD}(n=4)$. A two-way analysis of variance was used to analyze the difference between the threshold current of the epidural and intrathecal space, as well as the difference among the different spinal levels. Thereafter, statistical significance between the threshold current of the epidural and intrathecal space was determined using a paired $t$ 


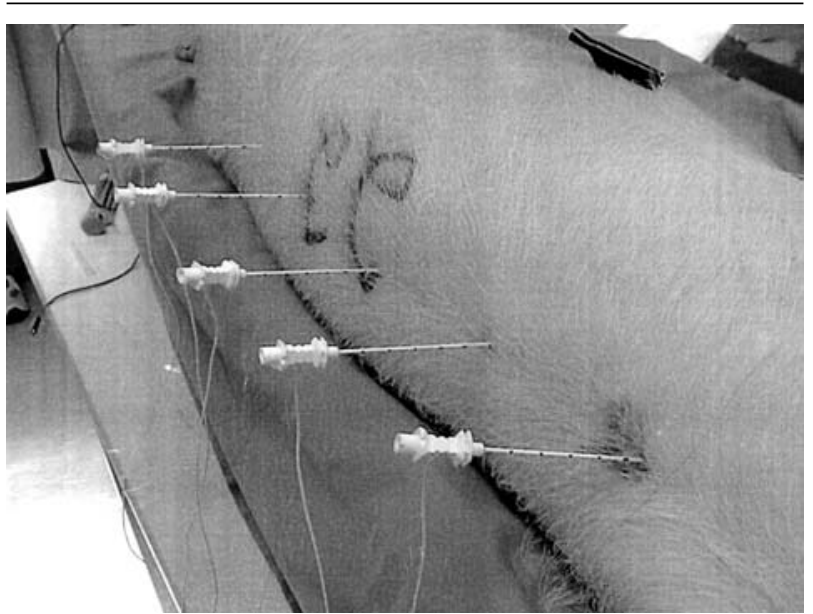

FIGURE 1 Five insulated Tuohy needles were inserted at five spinal levels.

test. Differences were judged to be significant when $P$ $<0.05$. The power of the study was determined by post hoc analysis.

\section{Results}

Figure 2 shows the current required (mean $\pm \mathrm{SD}$ ) to elicit a motor response in the epidural space and intrathecal space of the individual pigs. The mean threshold current in the epidural space for all four pigs was $3.45 \pm 0.14 \mathrm{~mA}$ ( $99 \%$ confidence interval of 3.04 to $3.86 \mathrm{~mA}$ ). Once in the epidural space, 18 needles were advanced a mean distance of $5.9 \mathrm{~mm}$ (range 5-8 $\mathrm{mm}$ ) before CSF was observed. In two separate pigs, the remaining two needles were advanced $1 \mathrm{~cm}$ in the high-thoracic region without obtaining CSF. The threshold current for these two needles was $4.5 \mathrm{~mA}$ and $2.8 \mathrm{~mA}$ in the epidural space and $0.4 \mathrm{~mA}$ and $0.3 \mathrm{~mA}$ after a $1-\mathrm{cm}$ advancement. Upon achieving the threshold current, these needles were advanced approximately $\mathrm{l} \mathrm{mm}$ at a time, whilst continuing to apply ES, until the needle contacted the bone. This required approximately, an additional $4 \mathrm{~mm}$ and $5 \mathrm{~mm}$, respectively. However, the minimum threshold current remained the same throughout the advancement at $0.4 \mathrm{~mA}$ and $0.3 \mathrm{~mA}$. The current required (mean $\pm \mathrm{SD}$ ) to elicit a motor response after the needle was advanced into the intrathecal space (until CSF was evident or until the needle was advanced a maximum of $1 \mathrm{~cm}$ ) was $0.38 \pm$ $0.13 \mathrm{~mA}$ (99\% confidence interval of 0.0 to $0.76 \mathrm{~mA}$ ) for the four pigs. There was no overlap in threshold current between the epidural space and intrathecal space

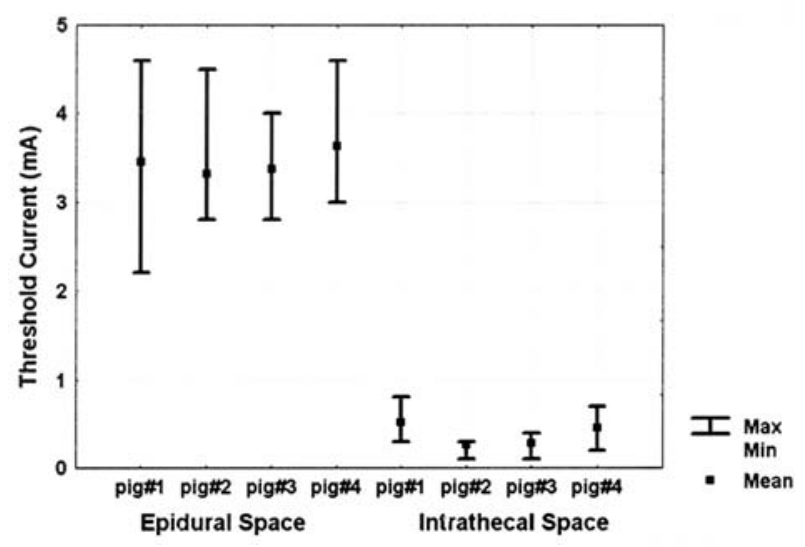

FIGURE 2 Threshold current in epidural and intrathecal spaces. The mean threshold current of stimulation in the epidural space was significantly higher than in the intrathecal space $(P<0.01)$.

for all pigs. In addition, the threshold current for motor activity obtained in the intrathecal or epidural space was not dependent on the spinal level (high-thoracic, midthoracic, low-thoracic, high-lumbar and low-lumbar levels) in each individual pig. There was a significant difference between the threshold current of the epidural and intrathecal space $(P<0.01)$. The power of the study, determined by post hoc analysis, was $>99 \%$.

\section{Discussion}

In this study, we demonstrated that, in a porcine model, the threshold current of an insulated needle required to elicit a motor response in the intrathecal space, was significantly lower than that in the epidural space. Results from this investigation, confirm the hypothesis of the Tsui test that there is a significant difference in the threshold current required to elicit a motor response with an insulated needle between the intrathecal and epidural space.

ES has many safe and useful medical applications. ${ }^{14-16}$ It has been applied to neural structures for neurophysiologic assessment, used as an effective method of pain management, and accepted as a useful tool for peripheral nerve location when performing regional anesthesia. ${ }^{14-16}$ The use of ES to confirm the location of the epidural space (Tsui test) has only recently been described..$^{7-12}$ This test appears to reliably confirm caudal, lumbar and thoracic epidural catheter placement in pediatric, obstetric and postoperative patients. ${ }^{7-12}$ None of the patients in these trials experienced any perioperative or postoperative discomfort or side-effects from ES. 
ES takes advantage of the distinct anatomic layers surrounding the spinal cord, each of which has its own conductive properties. Using this test with an insulated needle, one may determine the precise location of the epidural needle tip. We previously examined the effect of the test on the accuracy of caudal needle placement in anesthetized pediatric patients. ${ }^{17}$ Needle placement was judged to be either correct or incorrect depending on the presence or absence of anal sphincter contraction (S2-S4) at low current ES (1-10 mA). This and other studies have demonstrated the effectiveness of the test in confirming needle position in the caudal epidural space and support the concept that the test can be used to confirm insulated needle placement in the epidural space. ${ }^{17,18}$

A porcine model was selected in this study because epidural needle placement is similar in this model to that in humans. Also, $20 \mathrm{~kg}$ was chosen as an appropriate weight in order to simulate the pediatric patient population that is too large for caudal epidural placement and too small/young for unsedated, direct thoracic epidural placement. The epidural space was first identified using LOR to air. For this study, air was preferred over saline to avoid possible confusion between the injected saline and CSF. We carefully limited the amount of air $(<1 \mathrm{~mL})$ injected when performing LOR, in order to avoid any possible hindrance to electrical conduction. In clinical practice, saline may be preferred over air to avoid air lock.

Although the distance between the posterior epidural space to the intrathecal space has not been well established in pigs, a previous study demonstrated that the mean antero-posterior (AP) diameter of the spinal canal (T4 to L2 level) is $1.2 \pm 0.2 \mathrm{~cm} .{ }^{19} \mathrm{In}$ addition, $72 \%$ of the AP diameter of the spinal canal is occupied by the spinal cord in pigs. ${ }^{19}$ In our study, if CSF was not initially obtained we elected to advance the needle up to $1 \mathrm{~cm}$ beyond the epidural space in order to ensure the needle reached, but did not pass through, the intrathecal space. We advanced 18 needles a mean distance of $5.9 \mathrm{~mm}$ (range of 5-8 $\mathrm{mm}$ ) beyond the epidural space to obtain CSF. Another two needles were advanced $1 \mathrm{~cm}$ in the thoracic region without obtaining CSF. We believe there are two possible explanations for these observations. First, since these were the last needles inserted into the intrathecal space in these pigs, we speculate the absence of CSF was due to reduced CSF pressure, secondary to CSF loss from the previous needle placements, despite our estimation that only $0.3 \mathrm{~mL}$ of CSF would fill each needle. Another possibility is that the needle could have entered the spinal cord. This is based on previous observations that in pigs the $95 \%$ range of the entire AP diameter of the spinal canal is about 0.8 to $1.6 \mathrm{~cm}$ and $72 \%$ of the AP diameter of the spinal canal is occupied by the spinal cord. ${ }^{19}$ As the needles in our study were advanced $1 \mathrm{~cm}$ beyond the epidural space, it is very likely that they penetrated the spinal cord. In addition, the fact that the low threshold currents observed with these two needles remained unchanged as they were advanced from $1 \mathrm{~cm}$ beyond epidural space until bone was contacted (likely vertebral body), suggests these needles may have already been inserted into the intrathecal space at the $1 \mathrm{~cm}$ mark. Given that the threshold currents of these two needles were similar in range to those needles confirmed to be in the intrathecal space (with a free flow of CSF) and significantly lower than those obtained in the epidural space, we believe that this test can detect needle advancement beyond the epidural space even in absence of free flow of CSF.

In this study, there was no overlap in threshold currents between the epidural space and intrathecal space ( $99 \%$ confidence interval). Based on this information, ES may provide an additional, objective and reliable sign to the LOR technique for distinguishing entry of a needle into the epidural space from the intrathecal space. This test is not intended to replace the LOR technique when placing epidural needles in anesthetized patients, rather it is to be used in conjunction, to alert the clinician of possible needle proximity to the intrathecal space, spinal cord or nerve root. Although the use of a nerve stimulator for peripheral nerve blocks in anesthetized patients has not been shown to enhance safety, ES differs from peripheral electro-location. In confirming the presence of a needle or catheter in the epidural space, ES uses a supramaximal current $(>1 \mathrm{~mA}$ ) sufficient to stimulate any motor nerve structure within centimetres, while the principle goal of electro-location is to seek the minimum current required to stimulate a motor nerve within millimetres $(<0.5 \mathrm{~mA})$. By using supramaximal currents, proximity to any motor neural structure (nerve, nerve root or spinal cord) can be monitored while advancing the Tuohy needle using the LOR technique. However, because of the small number of animals studied to date, the milliamperage current settings for insulated needles are intended as guidelines and may require adjustment as experience increases.

One of the possible clinical applications of ES is to monitor epidural needle advancement. We hypothesize that one can apply ES with a constant current (99\% confidence limit for the epidural space; $3 \mathrm{~mA}$ for pigs based on this study) while advancing the insulated Tuohy needle using LOR technique with saline. Entry into the epidural space would be confirmed by 
LOR, however, any occurrence of a motor response with the chosen constant current $(3 \mathrm{~mA}$ for pigs) would serve as a warning signal that the needle has at least reached the epidural space (with 99\% confidence limit). Careful checking for LOR and/or threading of a catheter, as well as determining the threshold current should be performed prior to any further needle advancement. If, at any time, a motor response occurs when the current is below $1 \mathrm{~mA}$, proximity to a neural structure or entry into the intrathecal space should be suspected. Further advancement of the needle and injection of local anesthetic would not be advised, as it may risk injury or total spinal anesthesia. In this situation, any further attempt should be performed carefully at a different spinal level and follow-up would be advised to watch for any sign of adverse sequelae. Although damage may already have occurred from the needle insertion, this warning signal may avoid further injury from injection of a neurotoxic substance such as local anesthetic.

Information from ES can be rapid and useful in real time. ES may help to alert the anesthesiologist if a needle position needs to be re-evaluated or withdrawn to avoid possible complications. However, a negative motor response would not guarantee that the needle is a safe distance away from the spinal cord or nerve root. A false negative motor response may result from a number of different sources including malfunctioning equipment, pharmacological or pathological muscle paralysis or structural alteration in patients, or from operator error due to lack of familiarity or training. Thus, the ultimate decision regarding epidural safety should be based on a combination of current threshold, LOR and the anesthesiologist's clinical experience.

One limitation of this study is that the threshold current determined here may not be directly applicable to humans because the experiments were performed in pigs. In addition, the threshold current reported here may not apply to non-insulated needles as it is well documented that non-insulated needles require more current to stimulate nerves than do insulated needles. Nevertheless, this information can be used to design future clinical trials to determine the threshold current of entry into the intrathecal and epidural space in humans. Further studies will be needed to determine the role of ES in monitoring epidural needle advancement and preventing neurological injury.

\section{Acknowledgement}

The authors would like to thank Dr. S. Clanachan, Department of Pharmacology, University of Alberta for his contribution.

\section{References}

1 Bromage PR, Benumof JL. Paraplegia following intracord injection during attempted epidural anesthesia under general anesthesia. Reg Anesth Pain Med 1998; 23: 104-7.

2 Desparmet JF. Epidural anesthesia in infants (Editorial). Can J Anesth 1999; 46: 1105-9.

3 Krane EJ, Dalens BJ, Murat I, Murrell D. The safety of epidurals placed during general anesthesia (Editorial). Reg Anesth Pain Med 1998; 23: 433-8.

4 Kasai T, Yaegashi K, Hirose M, Tanaka $\Upsilon$. Spinal cord injury in a child caused by an accidental dural puncture with a single-shot thoracic epidural needle. Anesth Analg 2003; 96: 65-7.

5 Rose JB. Spinal cord injury in a child after single-shot epidural anesthesia. Anesth Analg 2003; 96: 3-6.

6 Raj PP, Rosenblatt R, Montgomery SJ. Use of the nerve stimulator for peripheral blocks. Reg Anesth 1980; 5: 14-21.

7 Tsui BC, Finucane B. Epidural stimulator catheter. Techniques in Regional Anesthesia and Pain Management. 2002; 6: 150-4.

8 Tsui BC, Gupta S, Finucane B. Detection of subarachnoid and intravascular epidural catheter placement. Can J Anesth 1999; 46: 675-8.

9 Tsui BC, Gupta S, Emery D, Finucane B. Detection of subdural placement of epidural catheter using nerve stimulation. Can J Anesth 2000; 47: 471-3.

10 Tsui BC, Guenther C, Emery D, Finucane B.

Determining epidural catheter location using nerve stimulation with radiological confirmation. Reg Anesth Pain Med 2000; 25: 306-9.

11 Tsui BC, Gupta S, Finucane B. Determination of epidural catheter placement using nerve stimulation in obstetric patients. Reg Anesth Pain Med 1999; 24: 17-23.

12 Tsui BC, Seal R, Koller J, Entwistle L, Haugen R, Kearney $R$. Thoracic epidural analgesia via the caudal approach in pediatric patients undergoing fundoplication using nerve stimulation guidance. Anesth Analg 2001; 93: 1152-5.

13 Passannante AN. Spinal anesthesia and permanent neurologic deficit after interscalene block. Anesth Analg 1996; 82: 873-4.

14 Nagle KJ, Emerson RG, Adams DC, et al. Intraoperative monitoring of motor evoked potentials: a review of 116 cases. Neurology 1996; 47: 999-1004.

15 North RB, Kidd DH, Zahurak M, James CS, Long DM. Spinal cord stimulation for chronic, intractable pain: experience over two decades. Neurosurgery 1993; 32: 384-95.

16 Wilson-Holden TJ, Padberg AM, Parkinson JD, Bridwell $K H$, Lenke LG, Bassett GS. A prospective comparison of 
neurogenic mixed evoked potential stimulation methods. Utility of epidural elicitation during posterior spinal surgery. Spine 2000; 25: 2364-71.

17 Tsui BC, Tarkkila P, Gupta S, Kearney R.

Confirmation of caudal needle placement using nerve stimulation. Anesthesiology 1999; 91: 374-8.

18 Singh $M$, Khan RM. Use of a peripheral nerve stimulator for predicting caudal epidural analgesia (Letter). Anaesthesia 2000; 55: 830-1.

19 Pampliega T, Beguiristain JL, Artieda J. Neurologic complications after sublaminar wiring. An experimental study in lambs. Spine 1992; 17: 441-5.

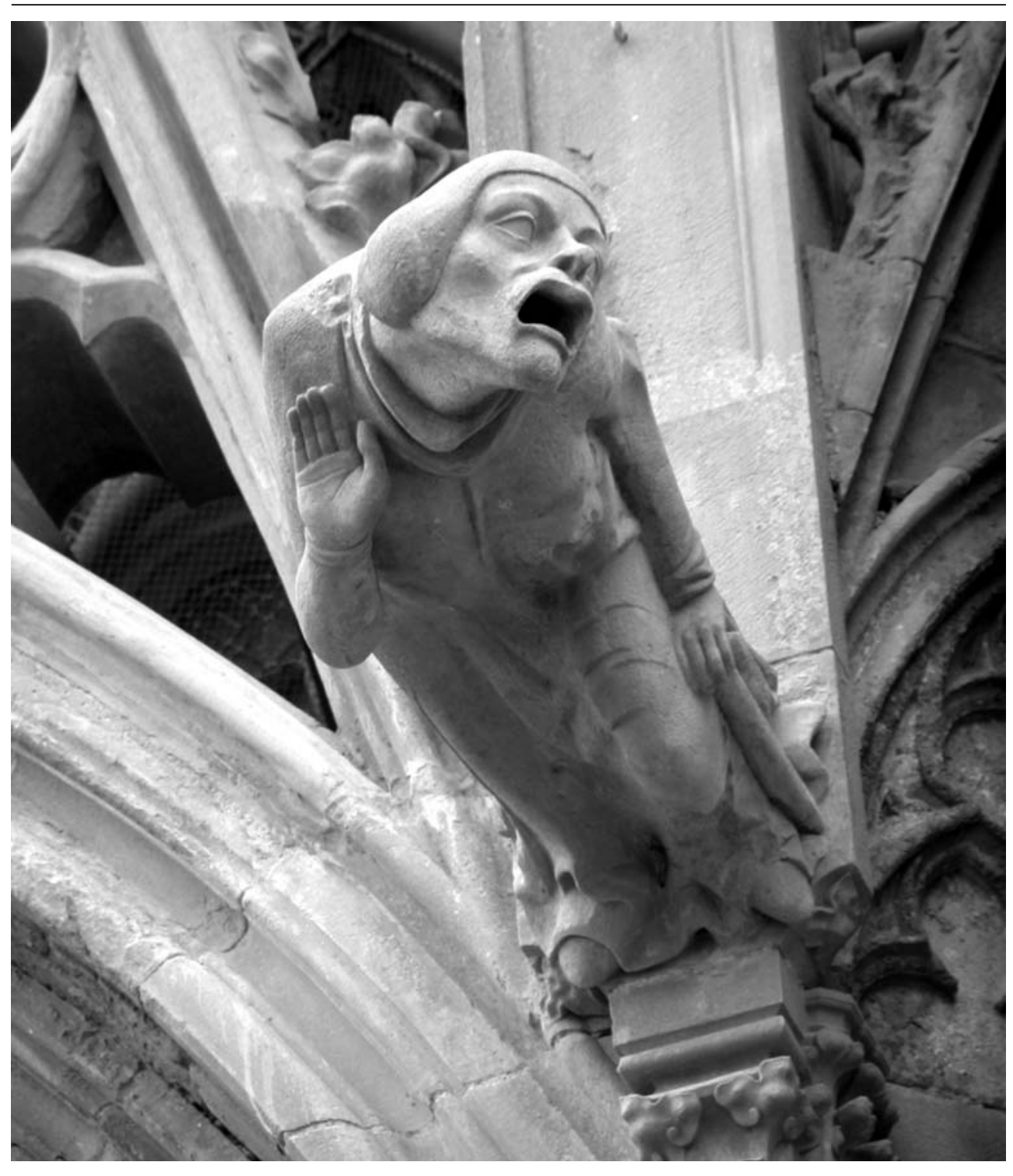

Carcassonne - France 